\title{
Immunterapi ved metabolsk syndrom
}

\begin{abstract}
Sykdommer assosiert med overvekt er et økende problem i store deler av verden. Musestudier avdekker en mekanisme bak sykdomsutviklingen samt en terapimulighet.
\end{abstract}

Overvekt gir økt risiko for utvikling av metabolsk syndrom, kjennetegnet ved bl.a. insulinresistens. Hva som ligger bak utviklingen av syndromet, vet man lite om, og det er begrensede muligheter for terapi.

En forskergruppe har i musemodeller vist at det er CD4-positive T-lymfocytter i visceralt fettvev som kontrollerer insulinresistensen (1). Undersøkelser av humant vev tyder på tilsvarende mekanisme hos mennesker. Forskerne behandlet også insulinresistente mus med immunterapi i form av CD3-spesifikke antistoffer. Denne behandlingen «opphevet» insulinresistensen hos musene. Det viste seg at behandlingen var effektiv i måneder etter injeksjonene på tross av fortsatt fettrik diett.

- Denne og andre studier understøtter antakelsen om at det er en nær forbindelse mellom immunitet og toleranse og omsetning av næringsstoffer, sier postdoktor Elisabeth Qvigstad ved Endokrinologisk seksjon, Oslo universitetssykehus, Rikshospitalet.

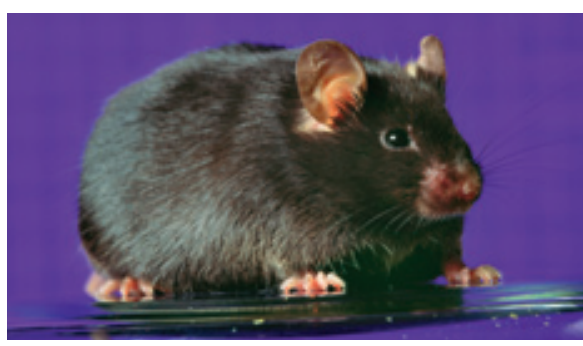

Fet laboratoriemus. Illustrasjonsfoto (C) George Steinmetz/Corbis/SCANPIX

- Studiene bidrar til forståelsen av hvordan inflammasjon er assosiert med det metabolske syndrom. Imidlertid kan vekttapet etter immunterapien også ha bedret glukosetoleransen. Det gjenstår å kartlegge hvilke signaler, for eksempel kjemokiner, som initierer T-celleaktivering i fettvev og om andre leukocytter bidrar i denne reaksjonen, sier Qvigstad.

\section{Åslaug Helland}

aslaug.helland@gmail.com

Tidsskriftet

\section{Litteratur \\ 1. Winer S, Chan Y, Paltser $G$ et al. Normalization of obesity-associated insulin resistance through immunotherapy. Nat Med 2009; 15: 921 -9.}

\section{Kostnader ved tidlig behandling av leddgikt}

\section{Behandling med sykdomsmodifise- rende legemidler i svært tidlig fase av revmatoid artritt bedrer livskvalitet og er kostnadsbesparende. Kostnads- effekten av biologiske legemidler er tvilsom.}

Behandling av revmatoid artritt i svært tidlig fase kan gi varig bedring i symptomer og livskvalitet, men valg av terapeutisk tilnærming er omdiskutert, bl.a. pga. kostnader.

I en simuleringsmodell med en hypotetisk pasientpopulasjon sammenliknet man tre ulike behandlingsstrategiers effekt på livskvalitet, sykdomsforløp og kostnader: metotreksat med eller metotreksat uten et biologisk legemiddel igangsatt $i$ tidlig sykdomsfase, eller en gradvis og symptomatisk tilnærming med ikke-steroide antiinflammatoriske midler (NSAID-preparater), analgetika og lavdosekortison og ev. sykdomsmodifiserende legemidler først etter ett år (1).

Tidlig behandling med metotreksat økte livskvaliteten mer enn en gradvis tilnærming og ga kostnadsgevinster, men var kostnadseffektivt kun uten bruk av biologiske legemidler. Ved sensitivitetsanalyser var biologiske legemidler kostnadseffektive først etter sterkt prisfall, betydelig reduksjon i dødsrisiko og sykdomsvarighet samt bedret pasientseleksjon.

- Helseøkonomiske analyser er nødvendig ved bruk av svært dyre legemidler, sier professor Ivar Sønbø Kristiansen ved Institutt for helseledelse og helseøkonomi, Universitetet i Oslo. Forfatternes modell er imidlertid ufullstendig beskrevet, og jeg mistenker at metodevalget innebærer en overvurdering av behandlingseffekten. Likevel tyder altså analysen på at prisen på de nye biologiske legemidlene mot inflammatorisk sykdom, bl.a. i ledd, er satt så høyt at midlene neppe er kostnadseffektive, sier Sønbø Kristiansen.

$$
\begin{aligned}
& \text { Petter Gjersvik } \\
& \text { petter.gjersvik@legeforeningen.no } \\
& \text { Tidsskriftet } \\
& \text { Litteratur } \\
& \text { 1. Finckh A, Bansback N, Marra CA et al. Treatment } \\
& \text { of very early rheumatoid arthritis with sympto- } \\
& \text { matic therapy, disease-modifying antirheumatic } \\
& \text { drugs, or biologic agents. A cost-effectiveness } \\
& \text { analysis. Ann Intern Med 2009; 151: 612-21. }
\end{aligned}
$$

\section{Rødvin til fisk?}

Det er allment akseptert at det er hvitvin og ikke rødvin som skal drikkes til fisk og skalldyr. En forklaring har vært at sjømat sammen med rødvin gir en ubehagelig fiskeaktig ettersmak i vinen. Men dette gjelder ikke alltid, og nå har japanske forskere kombinert smakstester med kjemisk analyse for å identifisere forbindelser som fører til usmak i et måltid med vin og kamskjell (J Agricult Food Chem 2009; 57: 8550-6).

Det var en sterk positiv korrelasjon mellom intensiteten på den fiskeaktige ettersmaken og konsentrasjonen av både totalt jern og toverdige jernioner. Når jerninnholdet i vinen var over ca. $2 \mathrm{mg} / \mathrm{l}$, var smaksopplevelsen dårlig. Dette var uavhengig av om vinen var rød eller hvit, men rødvin har som regel det høyeste jerninnholdet. Forskerne har ikke identifisert forbindelsen i kamskjell som kan reagere med vinen, men antyder at det kan være en umettet fettsyre.

\section{Enkel metode øker sjansen for graviditet}

På verdensbasis er intrauterin inseminasjon en svært vanlig behandlingsmetode ved ufrivillig barnløshet. Et uavklart spørsmål har vært om immobilisering etter inseminasjonen har effekt på graviditetsraten, og dette har nå har nederlandske forskere undersøkt (BMJ 2009; 339: b4080).

I en randomisert studie ble antall påbegynte graviditeter sammenliknet hos de 199 kvinnene som hadde vært immobilisert i 15 minutter etter inseminasjon linntil tre sykluser) med de 192 som umiddelbart var mobilisert. Graviditetsraten i immobilitetsgruppen var signifikant høyere enn i kontrollgruppen $(27 \%(n=54)$ versus $18 \%$ ( $\mathrm{n}=34)$; RR 1,5). Forklaringer kan være at medium med spermier lekker ut av uterus ved umiddelbar mobilisering, eller at spermiene bruker lengre tid til egglederne etter inseminasjon enn ved samleie $(2-10$ minutter).

\section{Luftforurensning årsak til appendisitt?}

Man har tidligere mistenkt at luftforurensning kan være medvirkende årsak ved appendisitt, ettersom man så en kraftig $ø$ kning i forekomsten under industrialiseringen. I en kanadisk pasient-kontroll-studie tok man for seg 5200 pasienter med appendisitt i perioden 1999-2006 (CMAJ 2009; 181: 591-7).

Risiko for appendisitt i forbindelse med kortvarige økninger i utvalgte luftforurensere ble estimert og kontrollert for temperatur, luftfuktighet, alder, kjønn og årstid. Hos menn var det i sommermånedene en sammenheng mellom økt luftforurensning og appendisitt, men dette gjenfant man ikke hos kvinner. 